\title{
Modification of graphene-oxide surface in nitrogen and argon glow discharge plasma
}

\author{
M. Mohai ${ }^{*}$ I. Bertóti \\ Institute for Materials and Environmental Chemistry, Research Centre for Natural Sciences, \\ Hungarian Academy of Sciences, P O Box 286, Budapest, H-1519 Hungary
}

\begin{abstract}
We performed glow discharge $\mathrm{N}_{2}$ or Ar plasma treatments of thin layers of graphene oxide (GO) deposited from slurry in alcohol onto stainless steel substrates. The treatment was performed in the preparation chamber of the X-ray photoelectron spectrometer, allowing reliable 'in situ' characterization of the treated surface by quantitative XPS. For the treatment 10 min plasma exposure was selected, based on preliminary experiments. Intensity of the treatment was enhanced by applying a negative bias between $0-300 \mathrm{~V}$ on the sample.

$\sim 10$ atomic $\%$ nitrogen was incorporated into the GO samples from $\mathrm{N}_{2}$ plasma within this short reaction time. When increasing the bias, the $\mathrm{N}$-content increased from 10 to 13 atomic \%, together with the decrease of the $\mathrm{O}$ content from the starting value of 29 atomic $\%$ to $\sim 15$ atomic $\%$. The reducing effect of Ar plasma was less pronounced, decreasing the oxygen content to $\sim 21$ atomic $\%$ only. The high resolution $\mathrm{C} 1 \mathrm{~s}, \mathrm{O} 1 \mathrm{~s}$ and N1s spectra show several different chemical states. The peak envelopes of the O1s and N1s lines could be decomposed to three, while the $\mathrm{C} 1 \mathrm{~s}$ spectrum to five different peaks of identical position for all samples. The component peaks were tentatively assigned to specific chemical bonding states. The relative amounts of $\mathrm{C}-\mathrm{O}$ and $\mathrm{C}-\mathrm{N}$ bonding states changed slightly with advancement of the treatment performed at increasing biases. It was established that the carboxyl- and the carbonyl-type $\mathrm{C}-\mathrm{O}$ clusters were more affected by both plasma treatments as their amount was selectively eliminated.
\end{abstract}

KEYWORDS: graphene oxide reduction, N-modified graphene oxide, glow discharge plasma, XPS quantification

\section{Introduction}

Covalent functionalization of different carbon materials, e.g., carbon nanotubes, graphene and graphene oxide (GO) surface has been the subject of numerous recent investigations aiming to tune their properties for different applications. Reliability of the results published so far is often suffering from insufficient characterization of the modified surface. We have been conducting detailed studies on this topic ${ }^{[1]-[3]}$.

Well-ordered nano-carbon materials, among others, multi-wall carbon nanotubes, graphene oxide, graphene due to their unique physical and chemical properties, are candidates for promising application in various areas ranging from novel structural materials, field emission

\footnotetext{
${ }^{*}$ Corresponding author, E-mail: mohai.miklos@ttk.mta.hu
} 
devices to pharmaceutical drug-delivery vehicles ${ }^{[4]-[7]}$. Many of these applications require some kind of surface modification of these materials. Moreover, surface groups may significantly influence the wettability, acid/base properties or even the shape of the carbon nanoparticles $^{[8],[9]}$.

Recently, we have investigated application of low-pressure radio frequency (RF) plasma activation of $\mathrm{N}_{2}$ and to explore this approach to the covalent attachment of the nitrogen to various carbon materials ${ }^{[10]}$. In this work thin films of graphene oxide, deposited on a stainless steel substrate holder, were treated by RF activated $\mathrm{N}_{2}$ and Ar gas plasma at nominally room temperature and the extent of the reduction and the amount of built-in nitrogen were studied by X-ray photoelectron spectroscopy (XPS), including also the evaluation of the chemical states of the components.

\section{Experimental}

\section{Sample preparation}

Commercial single layer graphene oxide (SLGO) (Cheap Tubes Inc, USA), was disaggregated in ethanol by ultrasonication. Thin films were prepared from this slurry by drop-wise deposition and drying onto a stainless steel XPS sample holder (Ø9 mm). The estimated thickness of the film was about one micron, which is much larger than the sampling depth of XPS.

Plasma treatment was performed in the stainless steel sample preparation chamber of the XPS instrument (base pressure $<1 \cdot 10^{-4} \mathrm{~Pa}$ ). The high purity $(5 \mathrm{~N}) \mathrm{N}_{2}$ or Ar flow of a few $\mathrm{cm}^{3} \cdot \mathrm{min}^{-1}$ (STP) was regulated by a bleeding valve that set the pressure to $3 \cdot 10^{-1} \mathrm{~Pa}$. Constant RF power of $100 \mathrm{~W}$ at $13.56 \mathrm{MHz}$ was applied through a matching circuit to a coil set outside of a glass dome fixed to the chamber. The sample bias was set to $0 \mathrm{~V}$ (earthed) or to negative values of 50 to $300 \mathrm{~V}$, varying the ion energy between 0 and $150 \mathrm{eV}$. A fixed 10 min treatment time was selected, based on some preliminary experiments. After treatment the samples were transferred to the analysis chamber without exposing them to the ambient air.

\section{Surface analysis}

X-ray photoelectron spectra were recorded on a Kratos XSAM 800 spectrometer operated at fixed analyzer transmission mode, using $\mathrm{Mg} \mathrm{K \alpha} \alpha_{1,2}(1253.6 \mathrm{eV})$ excitation. The pressure of the analysis chamber was lower than $1 \cdot 10^{-7} \mathrm{~Pa}$. The linearity of the energy scale was calibrated by the dual $\mathrm{Al} / \mathrm{Mg}$ anode method setting a $233.0 \mathrm{eV}$ kinetic energy difference between the two $\mathrm{Ag} 3 \mathrm{~d}_{5 / 2}$ lines. Survey spectra were recorded in the $150-1300 \mathrm{eV}$ kinetic energy range with $0.5 \mathrm{eV}$ steps. Photoelectron lines of the main constituent elements, i.e., the C1s, O1s and N1s were recorded by $0.1 \mathrm{eV}$ steps by $1 \mathrm{~s}$ dwell time. Spectra were referenced to the energy of the $\mathrm{C} 1 \mathrm{~s}$ line of the $\mathrm{sp}^{2}$ type graphitic carbon, set at $284.3 \pm 0.1 \mathrm{eV}$ binding energy.

Spectra were acquired and processed by the Kratos Vision 2 software package. Area intensity data were obtained after Shirley type background removal. Quantitative analysis were performed by the XPS MultiQuant 7.5 program $^{[11],[12]}$ using the experimentally determined photo-ionisation cross-section data of Evans et al. ${ }^{[13]}$ and asymmetry parameters of Reilman et al. $^{[14]}$. 


\section{Results and Discussion}

\section{Composition changes}

The composition of the as prepared GO sample and changes after 10 min plasma treatments are illustrated in Fig. 1. Only the alterations of the oxygen and nitrogen content are illustrated for clarity in atomic \%. Fig. 1a shows the dependence on the applied negative bias voltage and also on the actual ion energy. Here we consider that in the applied nitrogen plasma $\mathrm{N}_{2}{ }^{+}$ species are present and these are accelerated by the biasing electric field. When striking the surface they dissociate, and each $\mathrm{N}$ atom will possess in average half of the bias energy. Consequently, in order to compare the effect of the $\mathrm{Ar}^{+}$with that of the $\mathrm{N}_{2}{ }^{+}$at the same energy per bombarding atoms, half of the applied bias values should represent the energy in case of $\mathrm{N}_{2}$ plasma. Besides the effect of the ionized species the effect of excited neutrals, $\mathrm{Ar}^{0}$ and $\mathrm{N}_{2}{ }^{0}$ and also atomic $\mathrm{N}$ may be taken into consideration as reaction partners. Contribution of $\mathrm{N}$ atoms we could definitely neglect because of their very low quantity ${ }^{[\mathbf{1 5}]}$.

Energetic neutrals are mostly generated by charge exchange between accelerated by the field $\mathrm{N}_{2}{ }^{+}$ions and $\mathrm{N}_{2}{ }^{0}$ neutrals ${ }^{[16]}$. At zero bias the accelerating field, however, is absent. In addition, electron impact excitation may presumably contribute to the creation of the excited $\mathrm{N}_{2}$ states. As a consequence the "active species" in the plasma will react at zero and low biases only with specific "surface reaction sites" present on the GO sample. Further reactions, indicated by the increasing extent of the reduction and $\mathrm{N}$ incorporation, will only take place if the plasma is capable to generate further reaction sites. This happens at biases greater than 50-100 eV ion energy. Carbon vacancies and sites, left behind oxygen removal, could serve as reactive sites for further reactions.

In order to estimate the reacted zone inside the GO films (i.e., the thickness of the modified layer), the penetration depths of the $\mathrm{N}$ and Ar plasma ions, depending on their energy, are shown in Fig. 1b, as calculated by the SRIM-2013 (Stopping and Range of Ions in Matter) program $^{[17]}$, which computes the interaction of ions with matter based on Monte Carlo simulation method. We defined the GO target containing 25 atomic $\%$ O. While at very low energies of $20-50 \mathrm{eV}$ the depth is equal for the two ions, above $100 \mathrm{eV}$ the $\mathrm{N}$ ions of the same energy seems to penetrate somewhat deeper than Ar.

The composition data shows that at zero (no bias) and at $50 \mathrm{eV}$ ion energy similar oxygen loss happens. At increasing energy higher than $50 \mathrm{eV}$, the extent of reduction is further increasing. This latter observation could be related either to the deeper penetration of the ions or to the capability of creating both $\mathrm{C}$ and $\mathrm{O}$ recoils leading to new defect sites in the GO target. The former explanation is supported by the larger penetration of $\mathrm{N}$ than Ar with the same energy. This may be also a feasible explanation of the appreciably higher reduction achieved by the nitrogen plasma treatment.

An inverse trend of the build-up of nitrogen in the GO was detected. At zero (no bias) and at $50 \mathrm{eV}$ ion energy equally 10 atomic $\% \mathrm{~N}$ was measured, while at 100 and $150 \mathrm{eV}$ energy it increased to 13 atomic $\%$. We could detect a negligible amount (1-1.5 atomic \%) of $\mathrm{N}$ in the Ar plasma treated samples as well, possibly due to the nitrogen previously adsorbed on the chamber wall. 


\section{Chemical states changes}

The comparison of the high resolution $\mathrm{C} 1 \mathrm{~s}, \mathrm{O} 1 \mathrm{~s}$ and N1s lines of the as prepared and the Ar and $\mathrm{N}_{2}$ plasma treated samples are illustrated in Fig. 2. Both treatments significantly reduce the oxygen content. In case of $\mathrm{N}_{2}$ plasma, significant amount of nitrogen is incorporated also. These changes are also reflected on the $\mathrm{C} 1 \mathrm{~s}$ spectra: the $\mathrm{C}-\mathrm{O}$ components (at the high $\mathrm{BE}$ side) are decreased. In case of $\mathrm{N}_{2}$ treatment, this decrease is less pronounced, because of the simultaneous build-up of $\mathrm{C}-\mathrm{N}$ bonds.

The typical decompositions of the lines are shown in Fig. 3 for the case of the $\mathrm{N}_{2}$ plasma treated sample. The full width at half maximum (FWHM) of the component peaks were selected in accordance with the instrument resolution and kept equal for all components. Applying this approach, the $\mathrm{C} 1 \mathrm{~s}$ spectral line can be fitted by four (in case of $\mathrm{N}_{2}$ plasma by five), while the O1s and N1s lines by three components.

Assignment of these component peaks was made based on the large number of reliable literature data ${ }^{[1],[18]-[24]}$ and presented in Table 1.

As a qualitative assessment, the following main changes can be deduced from the line shape alterations (Fig. 2) and decomposition of the lines. In the as prepared samples the dominant $\mathrm{C} 1$ s components ${ }^{[18],[19]}$ are the $\mathrm{sp}^{2} \mathrm{C}-\mathrm{C}$ in graphene $(\mathrm{C} 0)$ and the carbonyl type $\mathrm{C}=\mathrm{O}(\mathrm{C} 2)$. The hydroxyl, ether and epoxy bonded carbon and the carboxylic $\mathrm{C}(\mathrm{C} 1, \mathrm{C} 3)$ are less intense. The Ar treatment reduces significantly the $\mathrm{C} 2$ and $\mathrm{C} 3$ components (Fig. 2). The $\mathrm{N}_{2}$ treatments induce similar changes but the concomitant incorporation of $\mathrm{N}$ in $\mathrm{C} 1, \mathrm{C} 2$ and $\mathrm{C} 3$ type $\mathrm{C}-\mathrm{N}$ bonds is masking of the reduction of those $\mathrm{C}-\mathrm{O}$ components (Table 1 ).

Both $\mathrm{Ar}$ and $\mathrm{N}_{2}$ plasma treatments reduce most significantly the $\mathrm{O} 3$ type O1s components. The $\mathrm{N}_{2}$ plasma treatments create three different $\mathrm{N}-\mathrm{C}$ bonds. Mainly the N1, slightly the N2 types are developed. Despite the high oxygen content of the pristine GO, N-O bonds are not developed at the applied conditions ${ }^{[25]}$.

Experiments, performed using similar conditions on other nanocarbon materials (e.g., graphene, nanotubes or graphite $)^{[1],[3],[10]}$, showed that similar chemical states were developed, although with different quantitative distributions.

\section{Conclusions}

- Comparison of the effect of the low pressure Ar and $\mathrm{N}_{2}$ plasma showed that both treatments reduced the $\mathrm{O}$ content of GO but in different extent.

- Significant reduction is taking place already at zero bias. Further reduction is initiated by applying a negative bias at or above $100 \mathrm{eV}$ ion energy.

- $\mathrm{N}_{2}$ plasma treatment seems to be more effective than the Ar plasma analogue, already at zero and also at all higher ion energy. This observation was related to the slightly deeper penetration of $\mathrm{N}$ than Ar ions at the same energy.

- Four different types of $\mathrm{C}-\mathrm{O}$ bonds were found by decomposing the $\mathrm{C} 1 \mathrm{~s}$ lines in as prepared state and also after all Ar plasma treatments.

- Carbonyl $(\mathrm{C}=\mathrm{O})$ and carboxyl $(\mathrm{O}-\mathrm{C}=\mathrm{O})$ bonding states seem to be more reactive, relative to others, showing significant decrease at all plasma treatments. 
- According to a number of published data, three types of $\mathrm{N}-\mathrm{C}$ bonds were detected in the $\mathrm{N} 1 \mathrm{~s}$ spectra after the $\mathrm{N}_{2}$ plasma treatments and there were assigned to specific bonding environments.

\section{Acknowledgements}

This work was sponsored by the National Scientific Research Fund (OTKA) through the project No. K-109558. Technical assistance of L. Gulyás is acknowledged.

\section{References}

[1] I. Bertóti, M. Mohai, K. László, Carbon 2015; 84, 185.

[2] J. Chen, X. Shi, S. Qi, M. Mohai, I. Bertóti, Y. Gao, H. Dong, Carbon 2015; 95, 338.

[3] Bertóti, M. Mohai, Cs. Balázsi, K. László, J. Szépvölgyi, Open Chem. 2015; 13, 451.

[4] C. Soldano, A. Mahmood, E. Dujardin, Carbon 2010; 48, 2175.

[5] Y. H. Hu, H. Wang, B. Hu, ChemSusChem 2010; 3, 782.

[6] T. Kuila, S. Bose, A. K. Mishra, P. Khanra, N. H. Kim, J. H. Lee, Prog. Mater. Sci. 2012; 57, 1061.

[7] L. Feng, L. Wu, X. Qu, Adv. Mater. 2013; 25, 168.

[8] A. Tóth, A. Törőcsik, E. Tombácz, E. Oláh, M. Heggen, C. Li, E. Klumpp, E. Geissler, K. László, J. Coll. Interface Sci. 2011; 364, 469.

[9] R. L. D. Whitby, V. M. Gun'ko, A. Korobeinyk, R. Busquets, A. B. Cundy, K. László, J. Skubiszewska-Zięba, R. Leboda, E. Tombácz, I. Y. Tóth, K. Kovács, S. V. Mikhalovsky, ACS Nano 2012; 6, 3967.

[10] I. Bertóti, I. Mohai, M. Mohai, J. Szépvölgyi, Diam. Relat. Mater. 2011; 20, 965; DOI: 10.1016/j.diamond.2011.05.011.

[11] M. Mohai, Surf. Interface Anal. 2004; 36, 828; DOI: 10.1002/sia.1775.

[12] M. Mohai, XPS MultiQuant for Windows User's Manual, Version 7.5, Budapest, 2015; http://www.chemres.hu/aki/XMQpages/XMQhome.htm.

[13] S. Evans, R. G. Pritchard, J. M. Thomas, J. Electron Spectrosc. Relat. Phenom. 1978; $14,341$.

[14] R. F. Reilman, A. Msezane, S. T. Manson, J. Electron Spectrosc. Relat. Phenom. 1976; $8,389$.

[15] N. Kang, S-G. Oh, F. Gaboriau, A. Ricard, J. Korean Phys. Soc. 2011; 59, 3031.

[16] A. Margulis, J. Jolly, Revue Phys. Appl. 1989; 24, 323.

[17] J. F. Ziegler, M. D. Ziegler, J. P. Biersack, Stopping and Range of Ions in Matter (SRIM2013), htpp://www.SRIM.org, 2013.

[18] D. Yang, A. Velamakanni, G. Bozoklu, S. Park, M. Stoller, R. D. Piner, S. Stankovich, I. Jung, D. A. Field, C. A. Ventrice Jr., R. S. Ruoff, Carbon 2009; 47, 145. 
[19] I-S. Byun, W. Kim, D. W Boukhvalov, I. Hwang, J. W. Son, G. Oh, J. S. Choi, D. Yoon, H. Cheong, J. Baik, H-J. Shin, H. W. Shiu, C-H. Chen, Y-W. Son, B. H. Park, NPG Asia Mater. 2014; 6, e102; DOI: 10.1038/am.2014.24.

[20] Y. Wang, Y. Shao, D. W. Matson, J. Li, Y. Lin, ACS Nano 2010; 4, 1790.

[21] H. K. Jeong, Y. P. Lee, R. J. Lahaye, M-H. Park, K. H. An, I. J. Kim, C-W. Yang, C. Y. Park, R. S. Ruoff, Y. H. Lee, J. Am. Chem. Soc. 2008; 130, 1362.

[22] Y-C. Lin, Ch-Y. Lin, P-W. Chiu, Appl. Phys. Lett. 2010; 96, 133110;

DOI: $10.1063 / 1.3368697$.

[23] H. Dai, X. Gao, E. Liu, Y. Yang, W. Hou, L. Kang, J. Fan, X. Hu, Diam. Relat. Mater. 2013; 38, 109; DOI: 10.1016/j.diamond.2013.06.012.

[24] G. Beamson, D. Briggs, High resolution XPS of organic polymers: The Scienta ESCA300 Database, John Wiley \& Sons, Chichester, 1992.

[25] J. L. Hueso, J. P. Espinós, A. Caballero, J. Cotrino, A. R. González-Elipe, Carbon 2007; $45,89$. 
Table 1. Assignment of the components of the C1s, O1s and N1s lines of the plasma treated graphene oxide samples ${ }^{[18]-[1]}$

\begin{tabular}{|c|c|c|}
\hline Component & Energy $(e V)$ & Chemical state \\
\hline $\mathrm{C} 0$ & $284.3 \pm 0.1$ & $\mathrm{sp}^{2} \mathrm{C}$ in graphene plane \\
\hline $\mathrm{C} 1$ & $285.8 \pm 0.2$ & $\begin{array}{l}\mathrm{C} \text { in hydroxyl, ether or epoxy bond, } \\
\mathrm{C}-\mathrm{N} \text { bond in pyridine ring or amine }\end{array}$ \\
\hline $\mathrm{C} 2$ & $287.4 \pm 0.2$ & $\begin{array}{l}\mathrm{C} \text { in carbonyl bond, } \\
\mathrm{C}-\mathrm{N} \text { bond in graphene plane }\end{array}$ \\
\hline $\mathrm{C} 3$ & $288.5 \pm 0.2$ & $\begin{array}{l}\mathrm{C} \text { in carboxyl or ester bond, } \\
\mathrm{C} \text { in amide bond }\end{array}$ \\
\hline $\mathrm{C} 4$ & $290.35 \pm 0.2$ & organic carbonate \\
\hline $\mathrm{O} 1$ & $530.6 \pm 0.3$ & O in carbonyl group \\
\hline $\mathrm{O} 2$ & $532.0 \pm 0.2$ & $\begin{array}{l}\mathrm{O} \text { in ether or epoxy, } \\
\mathrm{OH} \text { in alcohol, } \mathrm{C}=\mathrm{O} \text { in ester }\end{array}$ \\
\hline $\mathrm{O} 3$ & $533.4 \pm 0.3$ & $\begin{array}{l}\mathrm{C}-\mathrm{O}-\mathrm{C} \text { in ester, } \\
\mathrm{OH} \text { in carboxyl group }\end{array}$ \\
\hline N1 & $398.3 \pm 0.2$ & $\mathrm{sp}^{2} \mathrm{~N}$ in pyridine ring \\
\hline $\mathrm{N} 2$ & $399.7 \pm 0.2$ & $\mathrm{sp}^{2} \mathrm{~N}$ in pyrrol or diazine ring \\
\hline $\mathrm{N} 3$ & $400.9 \pm 0.2$ & $\mathrm{~N}$ substituting $\mathrm{C}$ in graphene plane \\
\hline
\end{tabular}



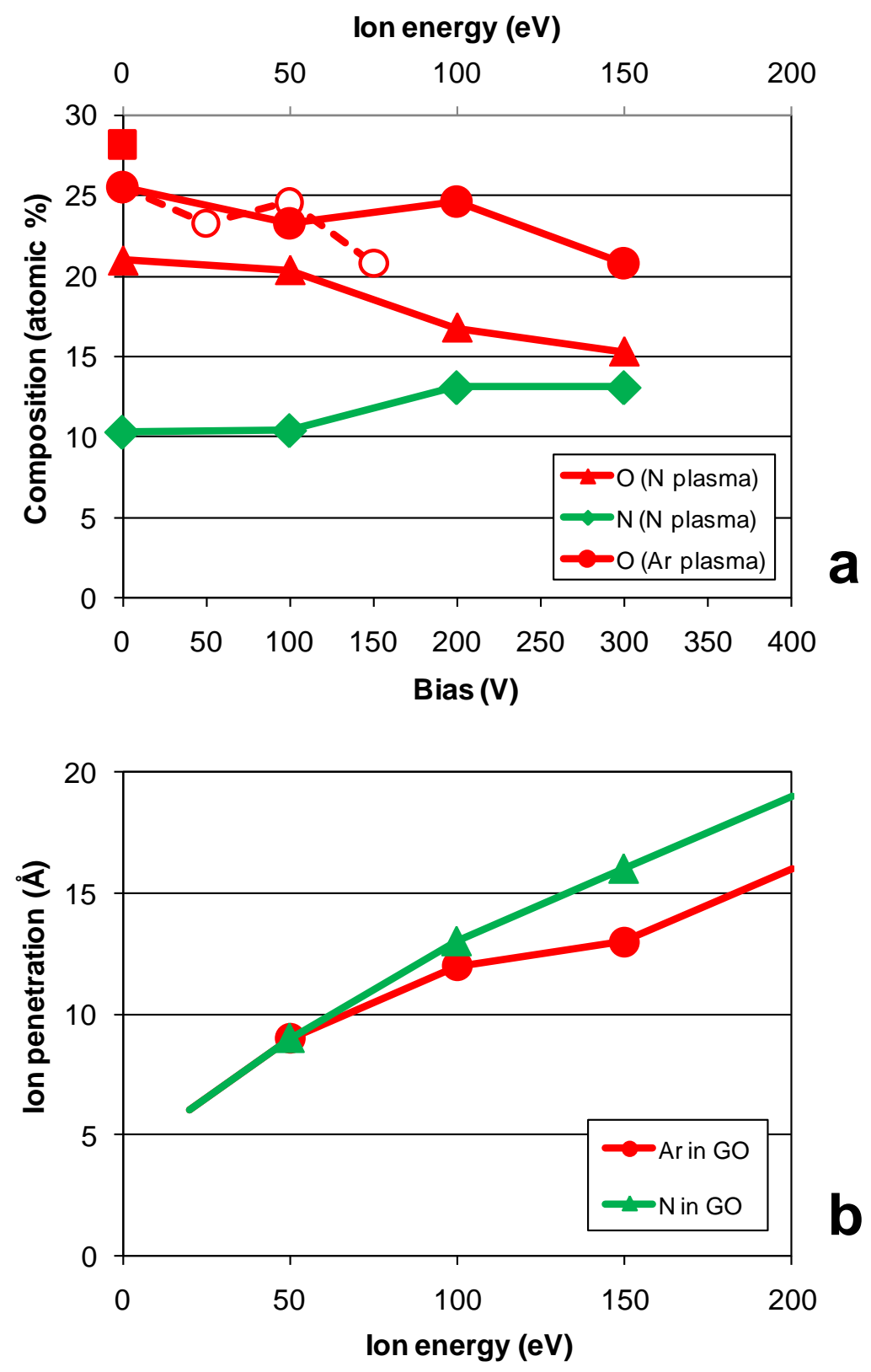

Fig. 1 (a) Changes of chemical compositions of GO during plasma treatments, as function of the applied bias $(\boldsymbol{\Delta} \diamond \mathrm{O})$ or of the ion energy $(\boldsymbol{\Delta} \bullet \mathbf{0})$. O content of the untreated GO (ם) is also marked. (b) The penetration depth of ions into GO, calculated by SRIM [12]. 

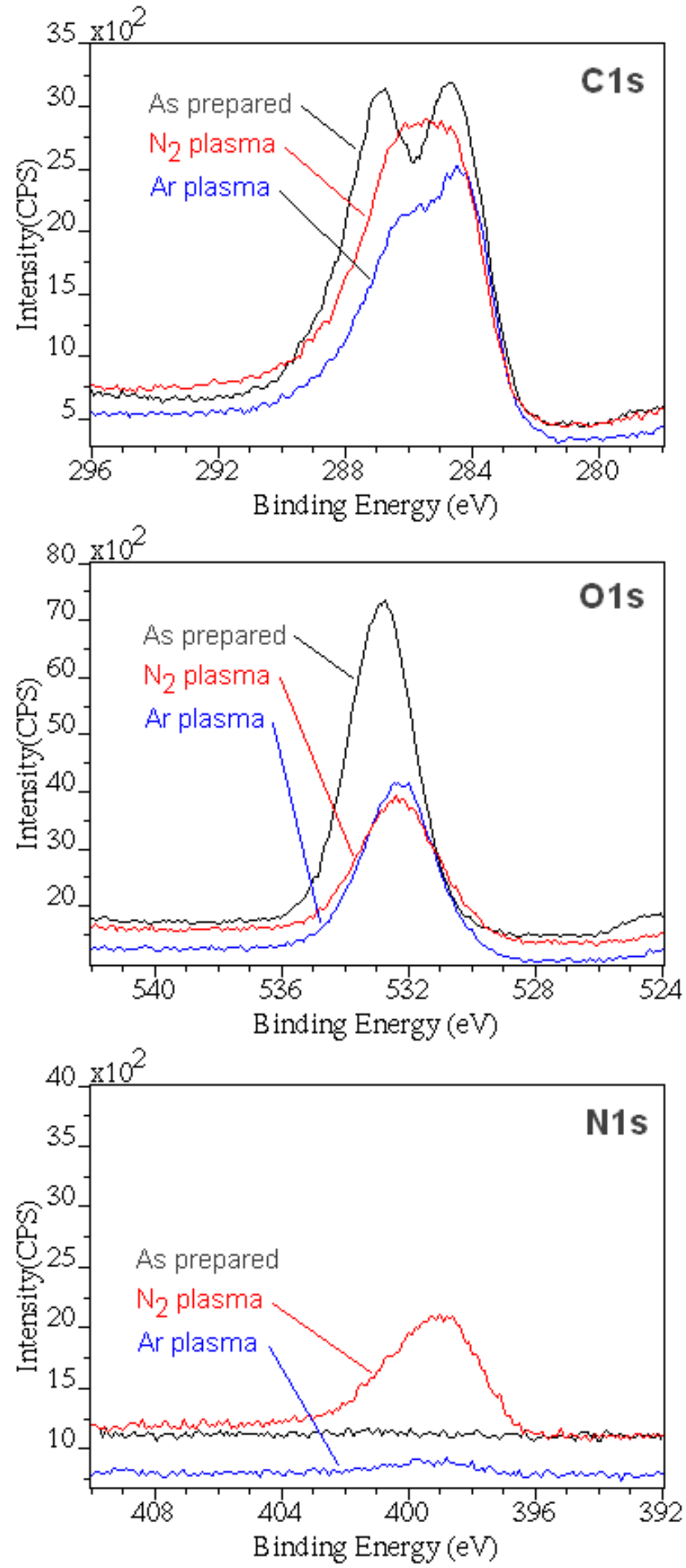

Fig. 2 Comparison of the shapes of the $\mathrm{C} 1 \mathrm{~s}, \mathrm{O} 1 \mathrm{~s}$ and N1s photoelecton lines of the as prepared and the $\mathrm{N}_{2}$ and Ar plasma treated (100 eV ion energy, $10 \mathrm{~min}$ ) samples. 

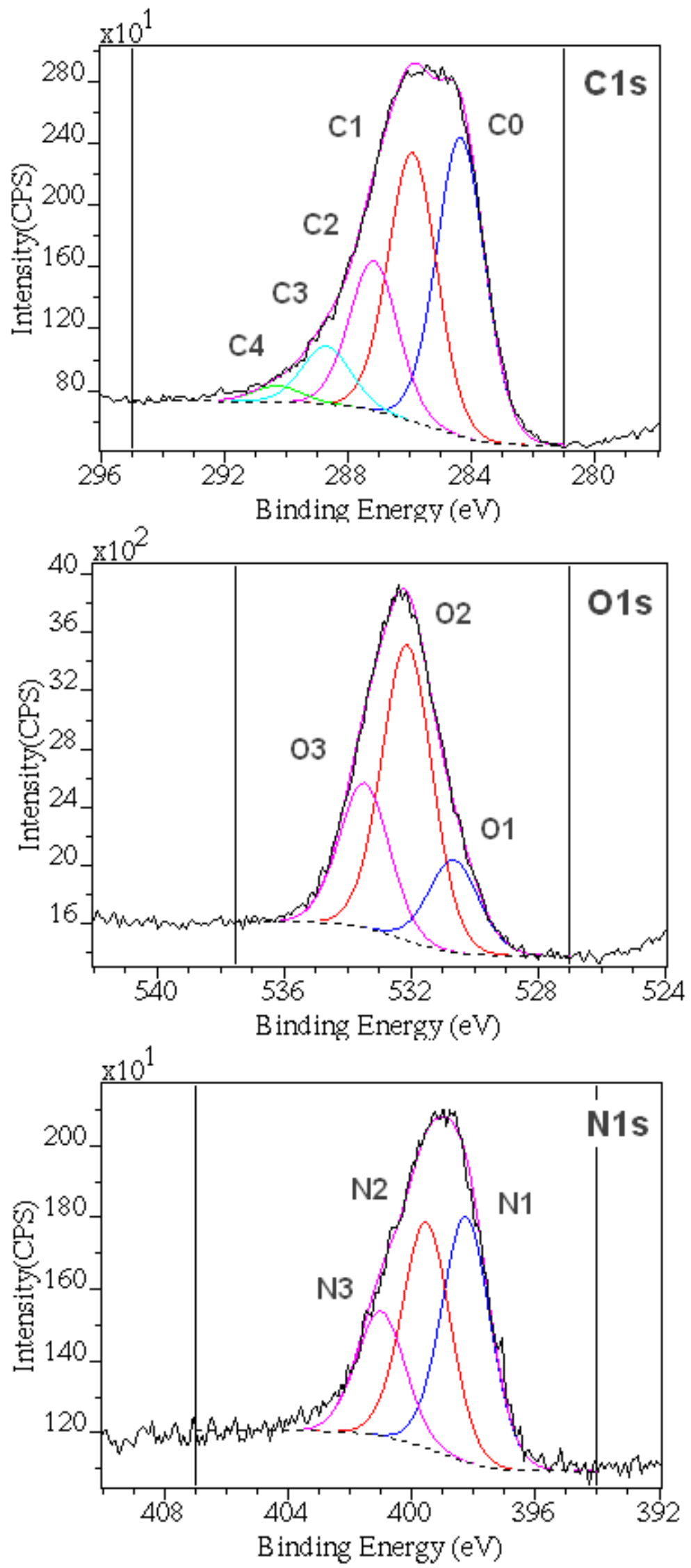

Fig. 3 Decomposition of the C1s, O1s and N1s photoelecton lines of the $\mathrm{N}_{2}$ plasma treated (100 eV ion energy, $10 \mathrm{~min}$ ) sample. 